\title{
Editorial on sintering centennial feature
}

Firing is the essential step in much of ceramics, but most of the discussion on firing in 1918 involved the vitrification of silicate ceramic, not the sintering of pure oxide ceramics. Only one paper in Volume 1 had "sintering" in its title. This was "Note on the Sintering of Magnesia", in June 1918 p 439-440, by John Ferguson of the Carnegie Institute of Washington. He was not addressing the conventional magnesia ceramic, which had $2 \% \mathrm{Mg}_{2} \mathrm{SiO}_{4}$ as a sintering aid. Rather it was pure $\mathrm{MgO}$, or as he said "silky, calcined, pure magnesia". Such a "silky calcined" powder was likely a nanosized powder, so perhaps this paper was the first report on sintering of synthetic nanopowders in our Journal. The $\mathrm{MgO}$ powder was held "for some hours at temperatures ranging from $1600^{\circ} \mathrm{C}-1720^{\circ} \mathrm{C}$ ". Ferguson reported that his colleague H.E. Merwin did a microscopic examination and observed that "crystals of periclase were interwoven to a considerable extent", so there was significant grain growth. He concludes that pure $\mathrm{MgO}$ ceramics of "sufficient mechanical strength" would be feasible "if the product were fired at temperatures between $1600^{\circ} \mathrm{C}$ and $1700^{\circ} \mathrm{C}$ for some hours". We should note that the motivation for Ferguson's note was the Great War, as his paper begins with the sentence "Prior to the war...ware made from magnesia was imported from Germany. This source of supply is now cut off and a new source has not yet appeared".

Ferguson's short note on sintering involved a pure nanopowder, very high temperature resistance heating, comments on grain growth, and microstructure analysisall of which are still important topics for our current sintering practice. In this issue, Raj Bordia, Suk-Joon Kang, and Eugene Olevsky bring us up to date with their Centennial Feature "Current understanding and future research directions at the onset of the next century of sintering science and technology."

John W. Halloran (iD Materials Science and Engineering, University of Michigan, Ann Arbor, Michigan 